\title{
Tourism Sector Employment Elasticity in Nepal: An Analysis
}

\author{
Resham Thapa-Parajuli ${ }^{1}$ \\ Ramesh C. Paudel ${ }^{2}$
}

\begin{abstract}
Given Nepal's location and geographical situation, the country has uniquecomparativeadvantages in the tourism sector. The Nepalese tourism sector largely remains labour-intensive due to insufficient investment in quality infrastructure and technology. Even in this background, the tourism sector contributes a significant share of GDP and employment in Nepal. Knowing the employment elasticities to various tourism indicators helps to understand the tourism sector and make sound policy inferences. For this purpose, the paper combinedthe annual data from the World Travel and Tourism Council (WTTC) on direct and indirect contribution to employment and GDP with the total tourist arrival and the average length of stay data from Nepal Tourism Statistics to estimate a simple double loglinear equation-based individual elasticity coefficients. The findings of this paper suggest that besides government personal travel and tourism spending, other all elasticities are positiv e. Among them, the average length of stay has the most substantial and positive employment elasticity coefficient, which is relatively higher than the total number of arrival elasticity too. Thus, it is better to target to extend the length of stay than the arrival of tourist, other things remaining the same.
\end{abstract}

Key Words: Tourism, Employment, Elasticity, Nepal.JEL classification code: L83, J21, O5

\section{Introduction}

Travel \& Tourism is one of the largest economic sectors in terms of employment. According to WTTC (2018), the tourism sector provides one in every tenth job worldwide and generates 10.4 percent global GDP. Moreover, the Travel \& Tourism industry experienced 3.9 percent growth, which is significantly higher than the worldwide growth in GDP (3.2 percemt). Furthermore, one in every five new jobs are from the tourism industry over the last five years (WTTC, 2018).

1 Mr. Thapa-Parajuli is an Assistant Professor at Central Department of Economics, TU.Email: resham3@gmail.com

2 Dr.Paudel is a visiting fellow at the Australian National University, Canberra, Australia. Email: Ramesh.paudel@alumni.anu.edu.au 
In the case of Nepal, the direct contribution of Travel \& Tourism to GDP in 2016 was 3.6 percent of the GDP and forecasts to rise by 6.8 percent in 2017 (WTTC, 2017). This figure is a reflection of the economic activities such as hotels, travel agents, airlines and other passenger transportation services excluding commuter services. It includes the activities of the restaurant and leisure industries directly supported by tourists (WTTC, 2016). The total contribution from the tourism sector is recorded at (including broader effects from investment, the supply chain and induced income impacts) 7.5 percent of GDP in 2016 and grew by 7.6 percent of GDP in 2017(WTTC, 2017).

Besides, such lions share contribution to the national GDP, tourism sector generates a large amount of direct and indirect jobs in Nepal. The tourism sectorcreated 427,000 jobs directly in 2016 (2.9 percent of total employment), and it grew by 6.0 percent in 2017 to 452,500 ( 2.9 percent of total employment). These jobs are from employment by hotels, travel agents, airlines and other passenger transportation services (excluding commuter services). It also includes the activities of the restaurant and leisure industries that directly cater to tourists (WTTC, 2017). The total contribution of Travel \& Tourism to employment (including broader effects from investment, the supply chain and induced income impacts) was 945,000 jobs in 2016 (6.4percent of total employment). It increased by 5.4 percent in 2017 , which is 996,000 jobs; a significant contribution totheNepalese economy (WTTC, 2017).

The tourism activities generate employment for unskilled living, particularlyin remote and rural areas. Since three-quarters of the two billion people under extreme poverty from developing countries live in rural areas, a potential for nature and culture-based tourism lies (UNWTO, 2016). Moreover, given Nepal's location and geography, the country has a natural advantage in tourism. The Government of Nepal, Ministry of Commerce and Supplies identifies tourism as the first exportable commodity having comparative advantage out of service categories which generates adequate job (MoCS, 2010). The identified strengths of the Nepalese tourism sector are-

i. Natural endowments,

ii. Attractive trekking areas,

iii. Rich in religious and cultural tourism,

iv. Service-oriented and courteous people and,

v. Innovative services and long experience of some travel operators

Indeed, it is a well-known tourist destination and is already well-established on the global tourism map. It is, therefore, natural to consider this as a sector having potential not only for growth in its contribution to the country's GDP but also for expanding employment in the sector.

In this context, this paper examines the employment elasticity of Nepalese tourism sector and estimates simple double-log-linear equations on total employment, direct employment and indirect employment on various tourism indicators in Nepalese tourism sector using annual data from WTTC that covers 2005 to 2018.The paper proceeds ahead by discussing various aspects of tourism and employment in Nepalin the following sections. 


\section{Tourism and Employment in Nepal}

Tourism is one of the largest industries in Nepal and one of the largest sources of foreign exchange and revenue. Nepal possesses eight world's highest peaks over 8000 meters in the world, Nepal is a hotspot destination for mountaineers, rock climbers and people seeking adventures. Hindu and Buddhist heritage attract many international tourists. Furthermore, Nepalesemoderately cold weather is also strong attractions. People often term Nepal as 'a place where there are more temples than houses' because it is rich in terms of its natural beauty and cultural heritage.It is a unique country inhabited by multi-lingual, multi-cultural and multi-ethnic people. It has got beautiful flora and fauna as natural gifts spread in Mountain, Hilly and Terai.

The tourism sector has higher linkages in the economy. According to Michelle, Stefan, Daniel, and Hall (2015), 'Tourism is a more diverse industry than many others. It has the potential to support other economic activities, both through providing flexible, part-time jobs that can complement other livelihood options and through creating income throughout a complex supply chain of goods and services'. Therefore, the tourism sector provides jobs for many unskilled and the marginal section of the society.

Tourism creates opportunities for many small and micro-entrepreneurs, either in the formal or informal economy; it is an industry in which start-up costs and barriers to entry are generally low or can easily be lowered. 'Tourism provides not only material benefits for the poor but also cultural pride. Tourism is labour intensive, which is particularly important in tackling poverty. It also provides a wide range of different employment opportunities especially for women and young people - from the highly skilled to the unskilled and generally, it requires relatively little training'(Michelle et al., 2015).

Table 1: Summary of Tourism Statistics

\begin{tabular}{|l|c|c|c|}
\hline \multicolumn{1}{|c|}{ Indicators } & $\mathbf{2 0 1 7}$ & $\mathbf{2 0 1 8}$ & Change in percent \\
\hline Total Revenue ('000 USD) & 658092 & 703179 & 6.41 \\
\hline Average Income per Visitor/day (USD) & 54 & 44 & -22.73 \\
\hline Hotel (Star) & 125 & 129 & 3.10 \\
\hline Hotel (Non Star) & 977 & 1125 & 13.16 \\
\hline Number of Hotel Beds & 39833 & 40856 & 2.56 \\
\hline Average Length of Stay & 12.60 & 12.40 & -1.59 \\
\hline Arrival(Air) & 760577 & 969287 & 27.44 \\
\hline Arrival(Land) & 179641 & 203785 & 13.44 \\
\hline Arrival(Total) & 940218 & 1173072 & 24.77 \\
\hline Travel Agencies & 3224 & 3508 & 8.10 \\
\hline Trekking Agencies & 2637 & 2649 & 0.45 \\
\hline Tourist Guide & 3876 & 4126 & 6.06 \\
\hline Trekking Guide & 13831 & 16248 & 14.88 \\
\hline
\end{tabular}

Source:Nepal Tourism Statistics, 2018. 
4 | The Economic Journal of Nepal (Issue No. 150)

The summary of basic tourism-related statistics is in Table 1 . Though the total revenue from the tourism sector increases by 6,41 percent during 2017-2018, the average daily expenditure made by tourists decreases significantly. The total star hotels, non-star hotels and total accommodation capacity increased significantly. All other fundamental tourism indicators improved right from total arrival to tourism-related agencies. However, the average length of stay reduced considerably. Therefore, it is rational to see the impact of these increasing and decreasing tourism parameters in employment generation capacity of the sector.

Table 2: Contribution of Travel and Tourism in 2018 (in Billion US\$)

\begin{tabular}{|l|l|l|l|}
\hline \multicolumn{1}{|c|}{ Nepal } & Global & Nepal & \multicolumn{1}{|c|}{ Rank } \\
\hline Direct $^{3}$ Contribution to GDP & 4053 & 0.8 & 120 \\
\hline Total $^{4}$ Contribution to GDP & 8800 & 1.6 & 122 \\
\hline Direct Contribution to Employment* & 207956 & 427 & 44 \\
\hline Total Contribution to Employment* & 319000 & 604 & 41 \\
\hline Travel \& Tourism Investment & 2160 & 16.5 & 123 \\
\hline Visitor Exports & 944 & 0.45 & 122 \\
\hline
\end{tabular}

Note: * in thousand

Sources:Satellite Account of Nepal Prepared by WTTC(2011)

3 The direct contribution of Travel \& Tourism to GDP reflects the 'internal' spending on Travel \& Tourism (total spending within a particular country on Travel \& Tourism by residents and non-residents for business and leisure purposes) as well as government 'individual' spending - spending by government on Travel \& Tourism services directly linked to visitors, such as cultural (e.g. museums) or recreational (e.g. national parks). The direct contribution of Travel \& Tourism to GDP is calculated to be consistent with the output, as expressed in National Accounting, of tourism-characteristic sectors such as hotels, airlines, airports, travel agents and leisure and recreation services that deal directly with tourists. The direct contribution of Travel \& Tourism to GDP is calculated from total internal spending by 'netting out' the purchases made by the different tourism sectors. This measure is consistent with the definition of Tourism GDP, specified in the 2008 Tourism Satellite Account.

4 The total contribution of Travel \& Tourism includes its 'wider impacts' (i.e. the indirect and induced impacts) on the economy. The 'indirect' contribution includes the GDP and jobs supported by (1) Travel \& Tourism investment spending - an important aspect of both current and future activity that includes investment activity such as the purchase of new aircraft and construction of new hotels; (2) Government 'collective' spending, which helps Travel \& Tourism activity in many different ways as it is made on behalf of the 'community at large' e.g. tourism marketing and promotion, aviation, administration, security services, resort area security services, resort area sanitation services, etc.; and (3) Domestic purchases of goods and services by the sectors dealing directly with tourists - including, for example, purchases of food and cleaning services by hotels, of fuel and catering services by airlines, and IT services by travel agents. The 'induced' contribution measures the GDP and jobs supported by the spending of those who are directly or indirectly employed by the Travel \& Tourism industry. 
Theoretical consideration for nature and culture-based tourism in Nepal and the nature of registered tourism enterprises reveals that Nepalese tourism is a labour-intensive one. According to WTTC (2018) satellite account recorded for 181 countries, the employment generated by the Nepalese tourism sector seems a remarkable one. It created 1031 thousand jobs in Nepal during 2017 alone, of which 427 thousand are direct jobs. In the world raking also it stands in $41^{\text {st }}$ position. So, the wise management of the tourism sector can be one of the potential employment generation strategies in Nepal. The tourism sector is contributing not only in the employment creations in Nepal; it also provides 1.6 billion US\$ equivalent to GDP in Nepal, which is a significant amount as such. Nevertheless, its world ranking in $122^{\text {nd }}$ suggests that employment in tourism is relatively less productive.

The WTTC (2018) and WTTC (2017) identified and estimated 15 different heads of the macroeconomic indicators. The summary of those indicators is in Table 3. First four indicators are visitors export, Domestic Expenditure, International tourism consumption and purchase of tourism providers which is supply chain; altogether they constitute the direct contribution of travel and tourism sector to GDP. Besides the supply chain, rests are growing, show the favourable effect to direct contribution to GDP. However, the slow growth of supply chain signals for weak backward and forward linkages of the sector.

Table 3: Contribution of Travel and Tourism in Nepal (in NPR Billion)

\begin{tabular}{|r|l|c|c|c|c|c|c|}
\hline SN & \multicolumn{1}{|c|}{ Years } & $\mathbf{2 0 0 5}$ & $\mathbf{2 0 1 0}$ & $\mathbf{2 0 1 5}$ & $\mathbf{2 0 1 6}$ & $\mathbf{2 0 1 7}$ & $\mathbf{2 0 1 8}$ \\
\hline 1 & Visitors export & 0.26 & 0.38 & 0.57 & 0.59 & 0.61 & 0.66 \\
\hline 2 & Domestic expenditure & 21.62 & 46.66 & 81.70 & 96.06 & 110.15 & 119.38 \\
\hline 3 & Internal tourism exp* & 33.07 & 74.32 & 142.20 & 163.94 & 185.04 & 203.89 \\
\hline 4 & Purchase by tourism ** & 10.56 & 11.01 & 19.79 & 23.32 & 26.27 & 28.28 \\
\hline 5 & Direct GDP Contribution (3+4) & 20.55 & 45.76 & 85.32 & 98.38 & 111.49 & 123.02 \\
\hline \multicolumn{7}{|c|}{ Other final impacts of Travel and Tourism (indirect \& induced) } \\
\hline 6 & Domestic supply chain & 22.51 & 63.32 & 122.41 & 140.63 & 158.77 & 175.61 \\
\hline 7 & Capital investment & 5.81 & 7.20 & 15.18 & 17.60 & 19.15 & 20.79 \\
\hline 8 & Govt. collective individual & 0.34 & 0.77 & 1.58 & 1.78 & 1.99 & 2.17 \\
\hline 9 & Indirect import & 5.86 & 13.62 & 28.92 & 29.27 & 30.05 & 32.45 \\
\hline 10 & Induced export & 11.45 & 27.66 & 60.50 & 67.88 & 74.89 & 84.50 \\
\hline \multicolumn{8}{|c|}{ Employment Generation ('000) } \\
\hline 12 & Direct employment & 285.86 & 347.43 & 426.40 & 452.05 & 475.82 & 497.91 \\
\hline 13 & Total employment & 717.44 & 761.40 & 918.54 & 968.17 & 1016.47 & 1062.28 \\
\hline \multicolumn{7}{|c|}{ Other indicators } \\
\hline 14 & Average length of stay (Day) & 9.09 & 12.67 & 13.16 & 13.40 & 12.60 & 12.40 \\
\hline 15 & Total arrival & 375.40 & 602.87 & 539.00 & 753.00 & 940.22 & 1173.10 \\
\hline
\end{tabular}

Note: $*\left(1+2+\right.$ Govt. individual spending); ${ }^{* *}$ (supply chain); ${ }^{* *}(5+6+7+8+9+10)$.

Source: Tourism Satellite Account Methodology (Tourism Satellite Account, 2008) 
Similarly, to estimate the total contribution, the paper considers the macroeconomic variable like domestic supply chain, capital investment, collective government spending, import from indirect spending, and induced expenditure must be clubbed with the direct contribution already calculated. Table-3revealsthat all the components are growing in their own pace as expected, but the import from indirect spending is gradually decreasing thought eh weight of this item is negligible. Thus altogether, the total contribution to the Nepalese economy from the travel and tourism sector seems growing annually and reached to about 248.3 billion rupees in 2018 . This fact reveals that tourism is one of the prominent sectors in Nepalese economy in future too.

\section{Employment Responsiveness of Tourism in Nepal}

Creation productive employment and decent work, though challenging, could be one of the strategies for Nepal to venture the Sustainable Development Goals (SDGs) by anticipated time. Every year more than half a million working people are in search of productive fulltime employment in the labour market. According to CBS (2018), there were approximately 20.7 million people of the working-age and about 7.1 million were employed, while 908 thousand were unemployed. Therefore, the unemployment rate records at 11.4 percent. The female unemployment rate is 2.8 percent above at 13.1 percent than the male counterpart. The unemployed labour force is predominantly unskilled. Tourism sector captures such a cohort as Michelle et al., (2015) rightly highlighted. Moreover, the Nepalese tourism sector is a lifeline for the livelihood options for needy people, as K. C. and Thapa Parajuli (2014) identify.

The labour market trends highlight the rise of low productive employment in the country and point at widespread low-quality jobs created in non-agricultural sectors. Its speed and extent reflect both the incentive and the ability of workers to move towards higher productivity sectors. Economic growth must take place for employment generation. The economic growth of Nepalis prolonged. During the period between 2000 and 2009, it generated growth of 3.77 percent per annum while employment growth is 2.21 percent annually less than the growth of the economically active population. An analysis of growth by economic sectors shows the service sector with high growth. Higher growth of the service sector is also accompanied by higher growth of employment in the sector. In this sector, the elasticity is also less than unity. As the elasticity coefficient accounts more than unity, it indicates that the productivity is low and decreasing. It also means lesser productive employment.

Within the tourism sector, this piece of work tries to explore how responsive is tourism sector employment (direct and total both) with a various tourism-related economic variable. The annual time series data set from Nepal tourism satellite account prepared by World Travel and Tourism Council and Tourism Statistics of Nepal areput together and analyzed. To estimate the elasticity coefficients of different heads double log-linear regression model without intercept is estimated using STATA-13 software. Necessary regression outputs like elasticity coefficient, coefficient of determination, F-value and Durbin-Watson statistics are in column (2), (3), (4) and (5) of Tables4 and 5. The problem of autocorrelation is corrected using Prais-Winston method; and transform the D-Wvaluesare reported. First, the elasticity coefficients for direct employment is estimated and reported in Table 4, then coefficients for total employment is calculated, which is reported in Table 5. 
The statistics reported in Tables 4 and 5 are respective elasticity coefficient of the direct and total employment generated by the tourism sector concerning various travel and tourism-related economic variables from 1995 to 2018. Out of eleven different variables identified and used, the average length of stay has most significant elasticity coefficients. The statistics reveal that as one percent average length of stay increases, one an average 2.27 percent direct and 2.61 percent other employment will increase in the economy. To be more precise, if the average length of stay, which is 12.67 these days in Nepal, increased to 13 days, on an average 17,323 direct and 19,918 total jobs would have been generated from travel and tourism sector alone, ceteris paribus. It reveals that the promotion of tourism to increase the length of stay would be one of the strategies to promote employment in Nepal, which further encourages economic growth too. The elasticity coefficient during the study period reveals that one percent more arrival adds only 0.54 and 0.57 extra direct and total jobs, ceteris paribus, which might be insufficient.

The statistic reveals that the travel and tourism direct and total contribution to GDP and employment has significantly positive relationships. As one percent direct contribution increases 1.55 and 1.23 percent direct and total employment increases respectively in Nepal. Similarly, one percent additional total contribution to GDP results from 1.41 and 1.61 percent respectively direct and total job creation in Nepal. It suggests that those policy devices which enhance tourism receipts in Nepal would be one of the robust strategies in tourism development in Nepal, which creates domestic jobs having multiplier effects. The visitors export alone is capable enough to generate 0.52 and 0.41 percent additional jobs with its each percentage increment. Though the landlocked economies need to bear the additional burden to export as identified by Paudel (2014), it is possible to createa more substantialcompensatory multiplier effect from tourism.

Table 4: Employment Elasticities (Direct Travel \& Tourism Employment)

\begin{tabular}{|l|c|c|c|c|}
\hline \multicolumn{1}{|c|}{ Headings } & Elasticity & $\mathbf{R}^{\mathbf{2}}$ & $\mathbf{F ( 1 , 2 3 )}$ & $\mathbf{D W}^{* *}$ \\
\hline Travel \& Tourism Direct Contribution to GDP & 1.55 & 0.72 & 59.27 & 0.93 \\
\hline Travel \& Tourism Total Contribution to GDP & 1.41 & 0.83 & 110.41 & 1.34 \\
\hline Visitor Exports & 0.52 & 0.64 & 41.50 & 1.02 \\
\hline Domestic Travel \& Tourism Spending & $0.03^{*}$ & 0.00 & $0.04^{*}$ & 1.89 \\
\hline Government Individual T\& T Spending & $-0.05^{*}$ & 0.01 & $0.17^{*}$ & 1.81 \\
\hline Internal Travel \& Tourism Consumption & 1.53 & 0.84 & 122.34 & 0.89 \\
\hline Leisure Travel \& Tourism Spending & 0.86 & 0.60 & 34.20 & 1.07 \\
\hline Business Travel \& Tourism Spending & 0.34 & 0.15 & 4.09 & 1.69 \\
\hline Capital Investment & $0.03^{*}$ & 0.00 & $0.08^{*}$ & 1.91 \\
\hline Total Arrival of Tourists & 0.54 & 0.90 & 192.82 & 1.70 \\
\hline Average Length of Stay ( Days) & 2.27 & 0.99 & 2395.33 & 1.84 \\
\hline
\end{tabular}

Note: *Insignificant and rest are significant at $1 \%$ level; **Transformed DW values

Source: Authors' calculation 
8 | The Economic Journal of Nepal (Issue No. 150)

Domestic travel and tourism spending and Capital investment are insignificant to create direct and total jobs in Nepal. Later one creates little bit jobs in Nepal, which must be due to induced activities that it elasticity coefficient to total employment is negligible but positive and significant. It might be the case that the critical minimum level of financing facilities are absent in Nepal. However, the growing financial sector backed by liberal policies might cater to tourism as well as the Sri Lankan case as identified in Paudel and Jayanthakumaran (2009) and Paudel (2007). The main challenge of the country over the past few years has been lack of investment for employment. Government has been allocating budget annually in sectors that can generate employment for skilled and unskilled labour. It is contradicting with the evidence put forward byUNWTO (2016) that claims investment in sustainable tourism can boost the sector's contribution to economic growth, development and particularly job creation, while at the same time addressing significant environmental challenges, according to the just-released. An investment of only 0.2 percent of global GDP per year would allow the tourism sector to continue to grow steadily over the coming decades, contributing to much-needed economic growth, employment and development while ensuring significant environmental benefit. It might be the case that our tourism sector is not capital intensive as it seems, and our investment is not heading towards sustainable tourism.

Table 5: Employment Elasticities (Dependent Variable: Total T \& T Employment)

\begin{tabular}{|l|c|c|c|c|}
\hline \multicolumn{1}{|c|}{ Headings } & Elasticity & $\mathbf{R}^{\mathbf{2}}$ & $\mathbf{F ( 1 , 2 3 )}$ & $\mathbf{D}-\mathbf{W}$ \\
\hline Travel \& Tourism Direct Contribution to GDP & 1.23 & 0.56 & 29.81 & 0.67 \\
\hline Travel \& Tourism Total Contribution to GDP & 1.61 & 0.84 & 119.62 & 1.07 \\
\hline Visitor Exports & 0.41 & 0.58 & 30.41 & 1.50 \\
\hline Domestic Travel \& Tourism Spending & $0.27^{*}$ & 0.10 & $2.42^{*}$ & 2.10 \\
\hline Government Individual T \& T Spending & -0.01 & 0.01 & $0.00 *$ & 1.84 \\
\hline Internal Travel \& Tourism Consumption & 1.68 & 0.81 & 99.74 & 0.71 \\
\hline Leisure Travel \& Tourism Spending & 0.59 & 0.51 & 23.66 & 0.79 \\
\hline Business Travel \& Tourism Spending & 0.49 & 0.23 & 6.99 & 1.47 \\
\hline Capital Investment & 0.20 & 0.15 & 3.94 & 2.25 \\
\hline Total Arrival of Tourists & 0.57 & 0.82 & 96.93 & 1.83 \\
\hline Average Length of Stay ( Days) & 2.61 & 0.99 & 2045.82 & 1.82 \\
\hline
\end{tabular}

Note: *Insignificant and rest are significant even at 1 percent level of significant;

**Transformed DW values

\section{Source: Authors'calculation}

Interestingly, government individual travel and tourism spending have negative employment elasticities. It must be the case that the expenditure made for this purpose is a kind of tourism import only. They visit a foreign destination without any forward and 
backward linkages in Nepal. It is further justified in the linkages analysis that the international airlines out of tourism-related activities have negative forward linkages in Nepal. It is the urgent need to correct such expenditure which does not promote employment in Nepal even its employment elasticities are negative signifying such activities contacts the available jobs.

International travel and tourism-related spending and employments have positive and significant relations that one percent extra such spending would create 1.53 and 1.68 percent additional direct and total jobs in Nepal. So, the promotion of such type of domestic-based tourism might be helpful to attain the employment targeting various policies in Nepal. The expenditure made for leisure travel and tourism also creates sufficient direct and induced jobs in Nepal that its elasticities are respectively 0.86 and 0.59 . The promotion of domestic tourism seems one of the viable strategies to promote tourism-led employment in Nepal. It is natural to claim that there is a huge potential for domestic tourism in Nepal. Moreover, business travel and tourism spending elasticities are also positive and significant. One percent extra expenses made for business travel and tourism will generate respectively 0.34 and 0.49 percent additional direct and total jobs in Nepal.

\section{Conclusion}

Given Nepal's location and geographical situation, the country has unique comparative advantages in the tourism sector.Considering nature and culture-based tourism in Nepal and the nature of registered tourism enterprises reveals that Nepalese tourism is a labour-intensive one. According to WTTC (2016) and WTTC (2017) satellite account recorded for 181 countries, the employment generated by the Nepalese tourism sector seems a remarkable one. The tourism sector is contributing not only in the employment creations in Nepal but also contributing 1.6 billion US\$ equivalent to GDP in Nepal, which is a significant amount as such. First four indicators are visitors export, domestic expenditure, international tourism consumption and purchase of tourism providers which is supply chain and altogether they constitute the direct contribution of travel and tourism sector to GDP.

One percent direct contribution to GDP increases 1.55 and 1.23 percent direct and total employment increases respectively in Nepal. Similarly, one percent additional total contribution to GDP results in 1.41 and 1.61 percent direct and total job creation respectively in Nepal. It suggests that those policy devices which enhance tourism receipts in Nepal would be one of the robust strategies in tourism development in Nepal, which creates domestic jobs having multiplier effects.Domestic travel and tourism spending and capital investment are insignificant to create direct and total employment in Nepal.

The government individual travel and tourism spending have negative employment elasticities. International travel and tourism-related expense and employments have positive and significant relations that one percent extra such spending would create 1.53 and 1.68 percent additional direct and total jobs in Nepal. The promotion of domestic tourism seems one of the viable strategies to promote tourism-led employment in Nepal. It is natural to claim that there is a huge potential for domestic tourism in Nepal. Moreover, business travel and tourism spending elasticities are also 
10 | The Economic Journal of Nepal (Issue No. 150)

positive and significant. One percent extra expenses made for business travel and tourism will generate respectively 0.34 and 0.49 percent additional direct and total jobs in Nepal.

The tourism sector has every potential to contribute to the national economy. Though global tourism is capital intensive, Nepal's one is labour-intensive as such. So, the tourism sector can be better developed in Nepal using the stock of underused labour in Nepal. Realizing this fact, Nepal should opt for rural or village tourism. It will enable the integration of this service sector to agriculture and informal sector, further enabling the distributive justice also.Targeting to increase the average number of stay would be better policies than the number of visitors in terms of job creation. However, some cross-cutting issues might impact the Nepalese economy and tourism. The adverse climate might cost to the economy as identified by Thapa-Parajuli and Devkota (2016) and some positive signals are there from highland tourism as identified by K.C. and Thapa-Parajuli (2015). The assumption is that those adversaries are in policy control and strength are in notice too.

Tourism sector seeks intensive use of information technology and modern amenities. The tourism entrepreneur needs to be informative regarding global context, language and culture. This kind of workforce can be produced by training the youths on it. So, there seems the immense potential of youth employment in this sector that various studies revealed that most of the thriving tourism workers are under 40 by ages and 42 percent female.

\section{References}

CBS (Cetral Bureau of Statistics)(2018). Report on the Nepal Labour Force Survey - 2017/18. Retrieved from Kathmandu: https://nepalindata.com/media/resources/items/20/ bNLFS-III_Final-Report.pdf

K. C, A., \& Thapa Parajuli, R. B. (2014). Tourism and its impact on livelihood in Manaslu conservation area, Nepal. Environment, Development and Sustainability, 16(5), 10531063. doi:10.1007/s10668-013-9512-7

K C, A., \& Thapa Parajuli, R. B. (2015). Climate change and its impact on tourism in the Manaslu Conservation Area, Nepal. Tourism Planning \& Development, 12(2), 225237.

Michelle, R., Stefan, G., Daniel, S., \& Hall, C. M. (2015). The global effects and impacts of tourism, The Routledge Handbook of Tourism and Sustainability: Routledge.

MoCS (Ministry of Commerce and Supplies) (2010). Nepal Trade Integration Strategy 2010: Executive Summary and Action Matrix. Retrieved from Kathmandu: ttp://www. mocs.gov.np/uploads/NTIS\%202010\%20exe\%20sum\%20160610.pdf

Paudel, R. C. (2007). Financial liberalisation in Sri Lanka: An econometric analysis. Austrlia: Wollongong University.

Paudel, R. C. (2014). Export performance in developing countries: A comparative perspective. Arndt-Corden Department of Economics, Crawford School of Economics.

Paudel, R. C., \& Jayanthakumaran, K. (2009). Financial liberalization and performance in Sri 
Lanka: The ARDL Approach. South Asia Economic Journal, 10(1), 127-156.

Thapa-Parajuli, R. B., \& Devkota, N. (2016). Impact of climate change on wheat production in Nepal. Asian Journal of Agricultural Extension, Economics \& Sociology, 1-14.

UNWTO (United Nation World Tourism Organization) (2016). Tourism and Culture Partnership in Peru: Models for Collaboration between Tourism, Culture and Community.

WTTC(World Travel and Tourism Council)(2016). Nepal Travel and Tourism: Economic Impact - 2016. http://www.wttc.org/-/media/files/reports/economic-impact-research/ countries-2016/nepal2016.pdf.

WTTC (World Travel and Tourism Council) (2017). The Economic Impact of Travel and Tourism in Nepal. Retrieved from London: https://www.wttc.org/-/media/files/ reports/economic-impact-research/archived/countries-2017-old/nepal2017.pdf

WTTC (World Travel and Tourism Council) (2018). Domestic Tourism: Importance and Economic Impact. Retrieved from UK: https://www.wttc.org/publications/2018/ domestic-tourism/ 